\title{
Identification of overexpressed genes in Sodalis glossinidius inhabiting trypanosome-infected self-cured tsetse flies
}

\author{
Illiassou Hamidou Soumana ${ }^{1}$, Bernadette Tchicaya ${ }^{1}$, Béatrice Loriod ${ }^{2,3}$, Pascal Rihet ${ }^{2,3}$ and \\ Anne Geiger ${ }^{1 *}$
}

1 IRD-CIRAD, UMR 177, Montpellier, France

2 INSERM, UMR1090 TAGC, Marseille, France

${ }^{3}$ Biology Department, Aix-Marseille University, Marseille, France

\section{Edited by:}

Monica Medina, Pennsylvania State

University, USA

\section{Reviewed by:}

Silvia Bulgheresi, University of

Vienna, Austria

Devin Coleman-Derr, Joint Genome

Institute, USA

*Correspondence:

Anne Geiger, UMR 177, IRD-CIRAD, CIRAD TA A-17/G, Campus

International de Baillarguet, 34398

Montpellier Cedex 5, France

e-mail: anne.geiger@ird.fr
Sodalis glossinidius, one of the three tsetse fly maternally inherited symbionts, was previously shown to favor fly infection by trypanosomes, the parasites causing human sleeping sickness. Among a population of flies taking a trypanosome-infected blood meal, only a few individuals will acquire the parasite; the others will escape infection and be considered as refractory to trypanosome infection. The aim of the work was to investigate whether fly refractoriness could be associated with specific Sodalis gene expression. The transcriptome of $S$. glossinidius harbored by flies that were fed either with a non-infected blood meal (control) or with a trypanosome-infected meal but that did not develop infection were analyzed, using microarray technology, and compared. The analysis using the microarray procedure yielded 17 genes that were found to have a significant differential expression between the two groups. Interestingly, all these genes were overexpressed in self-cured (refractory) flies. Further analysis of functional annotation of these genes indicated that most associated biological process terms were related to metabolic and biosynthetic processes as well as to oxido-reduction mechanisms. These results evidence the occurrence of molecular crosstalk between the different partners, induced by the passage of the trypanosomes through the fly's gut even though the parasites were unable to establish in the gut and to develop a permanent infection.

Keywords: sleeping sickness, tsetse-symbiont-trypanosomes, tripartite interactions, control flies, self-cured tsetse flies

\section{INTRODUCTION}

Tsetse flies (Glossina spp.), the vectors of African trypanosomes causing sleeping sickness in humans (HAT, human African trypanosomiasis) and nagana (AAT, animal African trypanosomiasis) in animals, harbor symbiotic bacteria that regulate important aspects of their host's physiology. Two of these microbes, obligate Wigglesworthia glossinidia and commensal Sodalis glossinidius, are vertically transmitted (Cheng and Aksoy, 1999; Dale and Maudlin, 1999) to developing intrauterine progeny via maternal milk gland secretions (Attardo et al., 2008). Tsetse's third symbiont, Wolbachia, is transmitted via the germ-line cells (Cheng et al., 2000; Balmand et al., 2013). While the prevalence of Wolbachia infections is high in laboratory-reared fly colonies (Cheng et al., 2000), field population prevalence is much lower, and several tsetse fly species were never shown to harbor the symbiont (Doudoumis et al., 2012); in fact, we did not evidence the presence of Wolbachia in the population of Glossina palpalis gambiensis from which the individuals used in our experiments were selected (Geiger, personal communication). Nevertheless, the association between some tsetse fly species and the symbiont may have a long co-evolutionary history, since Wolbachia loci were found horizontally transferred into the host genome (Doudoumis et al., 2012). S. glossinidius is a secondary symbiont located intra-extracellularly in the fly's midgut, but it can be detected in other tissues (Cheng and Aksoy, 1999; Balmand et al., 2013). The association between Sodalis and tsetse fly was suggested to be recent (Chen et al., 1999). In the wild, the prevalence of fly infection by trypanosomes seldom exceed $10 \%$ of the population (Frézil and Cuisance, 1994; Maudlin and Welburn, 1994); similarly, when flies are fed with a trypanosome-infected blood meal in the insectary (Ravel et al., 2003), less than $50 \%$ of the flies will acquire the parasite and, as in field conditions, most will escape infection. This means that the normal status of the flies is to be refractory to trypanosome infection. As concerns Sodalis, this symbiont was believed to be involved in fly vector competence in enhancing the trypanosome susceptibility of its host, the tsetse fly (Welburn and Maudlin, 1999). In the wild, the presence of Sodalis has been demonstrated to favor fly infection by trypanosomes, assessing the suggested role of the symbiont in vector competence (Farikou et al., 2010). The suggested mechanism involved included the inhibition of the trypanocidal lectin, secreted by the fly during feeding, by $\mathrm{N}$-acetyl glucosamine resulting from pupae chitin hydrolysis by chitinases secreted by the fly-hosted S. glossinidius (Maudlin and Ellis, 1985; Welburn et al., 1993; Welburn and Maudlin, 1999; Dale and Welburn, 2001). Finally, it was also shown that the effect of S. glossinidius could depend on its genotype (Geiger et al., 2007; Farikou et al., 2010). 
However, an overview of the biological mechanisms by which, in vivo, the bacteria favors fly infection, and, conversely, the mechanisms by which the fly becomes refractory to trypanosome infection, is still lacking. In this context, the aim of the present work was to investigate whether fly refractoriness could be associated with specific Sodalis gene expression. Consequently, the transcriptomes of $S$. glossinidius harbored by flies that were fed either with a non-infected blood meal (control) or with a trypanosomeinfected meal, but that did not develop infection, were analyzed using genome-wide $S$. glossinidius oligonucleotide microarrays and compared.

\section{MATERIALS AND METHODS ETHICAL STATEMENT}

The experimental protocols involving animals were approved by the Ethics Committee and the Veterinary Department of the Centre International de Recherche Agronomique pour le Développement (CIRAD), Montpellier, France. The experiments were conducted according to internationally recognized guidelines.

\section{TRYPANOSOMA BRUCEI GAMBIENSE STRAIN}

The S7/2/2 T. b. gambiense strain used in this study was isolated in 2002 from HAT-affected patients living in the sleeping sickness focus of Bonon, Côte d'Ivoire (Ravel et al., 2006). The strain belongs to the homogenous T. b. gambiense group 1 .

\section{INFECTION OF GLOSSINA PALPALIS GAMBIENSIS}

The G. p. gambiensis flies used in this study originate from flies that were collected in the field in Burkina Faso. Pupae were collected from these flies. Following fly emergence, the population was maintained in a level- 2 containment insectary at $23^{\circ} \mathrm{C}$ and $80 \%$ relative humidity (Geiger et al., 2005) without any selection. Individuals used in the present work were randomly chosen for infection experiments.

Experimental infections were conducted following the protocol reported by Ravel et al. (2006). T. b. gambiense stabilate was thawed at room temperature and $0.2 \mathrm{ml}$ was injected intraperitoneally into balb/cj mice. The infection was monitored by examining tail blood using a phase-contrast microscope at a $\times 400$ magnification. Teneral flies were then fed for the first time on infected mice displaying parasitemia levels between 15 and $25 \times 10^{7}$ parasites $/ \mathrm{ml}$ (determined using the matching method, Herbert and Lumsden, 1976). Ten days after infected bloodmeal uptake, an anal drop was collected from each fly, and the fly infection status was determined by PCR examination using TBR specific primers (Moser et al., 1989) assessing the presence or absence of trypanosomes. Positive PCR results indicate trypanosome establishment in the fly midgut; negative PCR results indicate trypanosome self-cured flies. Less than 5\% of the flies that were exposed to trypanosome were shown to be infected at day 10 post-infected blood-meal uptake. Only flies whose PCR result was negative were included in this study; they were designated as self-cleared or as refractory flies. Negative control samples consisted in teneral flies fed for the first time on noninfected mice. Finally, all the flies (fed on infected or non-infected mice) were later maintained by feeding on an uninfected rabbit,
3 days a week. Ten days after the first blood feeding (on either trypanosome infected or non-infected mice), the flies were dissected according to the method described by Penchenier and Itard (1981), and the samples, each of seven pooled midguts, respectively from control and refractory flies, were collected in $400 \mu \mathrm{l}$ of RNA later (Ambion, France).

\section{RNA ISOLATION}

Total RNA was extracted from each sample using Trizol reagent (Invitrogen, France) according to the manufacturer's specifications. After extraction, RNA integrity was checked using agarose gel electrophoresis. The quality of RNA and the absence of any DNA contamination were checked on an Agilent RNA 6000 Bioanalyzer and quantified using the Agilent RNA 6000 Nano kit (Agilent Technologies, France).

\section{CDNA HYBRIDIZATION ON MICROARRAY}

RNA reverse transcription and fluorescent dye incorporation were carried out using the Promega ChipShot Direct Labeling and Clean-Up System (Promega, USA). For each sample, $5 \mu \mathrm{g}$ of total RNA was reverse-transcribed and labeled with a single dye (Cy3) labeling procedure and used for microarray hybridization according to the manufacturer's indications (Promega). Each sample was run on custom-made 60-mers oligonucleotide microarrays specific for the S. glossinidius whole genome, and for the four plasmids (respectively, GenBank accession number, AP008232; NCBI RefSeq: NC_007183.1; NCBI RefSeq: NC_007184.1; NCBI RefSeq: NC_007186.1; NCBI RefSeq: NC_007187.1) with at least four oligonucleotide probes per gene (design is available at Gene Expression Omnibus under the accession number GPL17347). The Agilent design utilizes the uniqueness of probe sequences as one of the criteria for probe selection to avoid cross-hybridization with non-target genes. For each experimental condition four independent biological replicates were analyzed to ensure the high reproducibility and statistical significance of the expression data. The details of the expression data are available at Gene Expression Omnibus under accession number GSE48360.

\section{MICROARRAY DATA ANALYSIS}

The primary expression data were normalized through two successive steps using (a) both $\mathrm{R}$ software packages and lowess normalization to normalize the $\mathrm{M}$-values for each array separately (within-array normalization) without prior background correction, and (b) quantile normalization to the $A$-values, making the density distributions similar across arrays to compare expression intensities between them (Bolstad et al., 2003). Normalized expression values were averaged through $\mathrm{Cy} 3$ signal intensities according to dye-swap replications to assign only one expression value to each biological replicate. Microarray data were scanned using an Agilent microarray scanner (Agilent Technologies), and the pictures were extracted with Agilent Feature Extraction software (version 10.5.1.1). Data were filtered for detectable expression level; only those showing a level of expression greater than the background noise in at least three of the four replicates were selected.

Unsupervised hierarchical clustering was used to investigate relationships between samples and between genes. It was applied 
to median-centered data, using the Cluster and TreeView programs (average linkage clustering using Pearson correlation as the metric distance). Statistical analysis was performed using the TMeV5 Multi Experiment Viewer, v4.5 software (http://www. tm4.org/mev.html) and two-class unpaired SAM (significant analysis of the microarray program) analysis method. One-way analysis of variance was applied to identify genes differentially expressed between infection self-cured and control flies. A 5\% predicted false discovery rate was used as the threshold for differential expression (Reiner et al., 2003).

The identification of biological interpretation of differentially expressed genes was performed using DAVID software (Dennis et al., 2003). This program allows identification of the biological interpretation of genes in the basis of gene ontology (GO) terms. In addition, the Kyoto Encyclopaedia of Genes and Genomes (KEGG) pathways were used to assess the specific biological pathways that were overrepresented.

\section{QUANTITATIVE REAL-TIME PCR}

The microarray results were controlled, using quantitative PCR (qPCR), on a subset of four genes (SG0845, SG0858, SG0895, and SG1978) that were shown to be differentially expressed in microarray experiments between the two groups of flies; these genes were among the highest overexpressed in refractory flies. Primers, specific to these genes (Table 1) were designed using Primer-Blast software (http://www.ncbi.nlm.nih.gov/tools/ primer-blast/). cDNA was synthesized from $5 \mu \mathrm{g}$ of original total RNA samples using random hexamers and Superscript II reverse-transcriptase (Invitrogen, France) according to the manufacturer's instructions. All qPCR reactions were performed in an Mx3005P QPCR System (Agilent Technologies) using the Brillant II Sybrgreen qPCR Kit (Agilent technologies) with $2 \mu \mathrm{l}$ of cDNA of a known concentration in a $25-\mu$ l total volume. PCR efficiencies for each primer pair were calculated using tenfold dilutions of fly gut-extracted cDNA as previously described (Hamidou Soumana et al., 2013). PCR conditions were as follows:

Table 1 | Primers designed for microarray data confirmation by quantitative PCR (qPCR).

\begin{tabular}{llcc}
\hline Primer & Sequence $\left(\mathbf{5}^{\prime} \rightarrow \mathbf{3}^{\prime}\right)$ & $\begin{array}{c}\text { Concentrations } \\
\text { (nM) }\end{array}$ & $\begin{array}{c}\text { Amplicon } \\
\text { size (bp) }\end{array}$ \\
\hline SG0845F & GCCAGCCTTATGTGGAAGGT & 600 & 140 \\
SG0845R & AGCCGGGGTGACTTTAGTTG & 600 & \\
SG0858F & GTTCATTCTCGGTCTGCCCA & 600 & 136 \\
SG0858R & GGCGGGTAAGCCGACATATT & 600 & \\
SG0895F & CGACCTGGTTATTAGCGGCA & 300 & 121 \\
SG0895R & CGCTACGTTATCCACCGACA & 900 & \\
SG1978F & ACCACTGCAACCGTTTTTCG & 300 & 153 \\
SG1978R & GCAGCTTATGACCGTCTCGT & 150 & \\
Gmm Tub F & CCATTCCCACGTCTTCACTT & 600 & 149 \\
Gmm Tub R & GACCATGACGTGGATCACAG & 600 & \\
\hline
\end{tabular}

Primers were designed with Primer-Blast software. The third and fourth columns represent forward and reverse primer concentration used in QPCR and PCR product size obtained, respectively. $94^{\circ} \mathrm{C}$ for $5 \mathrm{~min}(1 \times)$, followed by $94^{\circ} \mathrm{C}$ for $45 \mathrm{~s}, 60^{\circ} \mathrm{C}$ for $45 \mathrm{~s}$, $72^{\circ} \mathrm{C}$ for $1 \mathrm{~min}(39 \times)$, and then $72^{\circ} \mathrm{C}$ for $10 \mathrm{~min}(1 \times)$. Melting curve analysis was performed to check the specificity of the PCR reaction and to verify the amplification efficiency. The housekeeping gene, Glossina tubulin (GenBank accession number HE861503), was used as the reference gene for the normalization

Table 2 | List of $\boldsymbol{S}$. glossinidius significantly differentially expressed genes in microarray experiment using SAM procedure with a $5 \%$ false discovery rate.

\begin{tabular}{|c|c|c|c|}
\hline $\begin{array}{l}\text { Oligonucleotide } \\
\text { probe }\end{array}$ & $\begin{array}{l}\text { GenBank } \\
\text { accession } \\
\text { number }\end{array}$ & Description & $\begin{array}{l}\text { Fold } \\
\text { change }\end{array}$ \\
\hline SOD_P10175 & SG2357 & Phage capsid protein & 1.5 \\
\hline SOD_P4185 & SG0858_nagB & $\begin{array}{l}\text { Glucosamine-6-phosphate } \\
\text { deaminase }\end{array}$ & 1.5 \\
\hline SOD_P4185 & SG0858_nagB & $\begin{array}{l}\text { Glucosamine-6-phosphate } \\
\text { deaminase }\end{array}$ & 1.4 \\
\hline SOD_P5905 & SG1285 & Hypothetical protein & 1.5 \\
\hline SOD_P6235 & SG1367 & $\begin{array}{l}\text { UTP-glucose-1-phosphate } \\
\text { uridylyltransferase }\end{array}$ & 1.7 \\
\hline SOD_P4337 & SG0895 & Galactokinase & 1.5 \\
\hline SOD_P9701 & SG2237 & $\begin{array}{l}\text { Serine/threonine protein } \\
\text { kinase }\end{array}$ & 1.3 \\
\hline SOD_P7410 & SG1659 & Hypothetical protein & 1.3 \\
\hline SOD_P1886 & SG0301_dipZ & $\begin{array}{l}\text { Thiol:disulfide interchange } \\
\text { protein }\end{array}$ & 1.2 \\
\hline SOD_P7169 & SG1597 & $\begin{array}{l}\text { NADH dehydrogenase I } \\
\text { subunit F }\end{array}$ & 1.4 \\
\hline SOD_P7309 & SG1632 & Lipoprotein precursor & 1.3 \\
\hline SOD_P4186 & SG0858_nagB & $\begin{array}{l}\text { Glucosamine-6-phosphate } \\
\text { deaminase }\end{array}$ & 1.6 \\
\hline SOD_P4186 & SG0858_nagB & $\begin{array}{l}\text { Glucosamine-6-phosphate } \\
\text { deaminase }\end{array}$ & 1.7 \\
\hline SOD_P324 & pSG1GP_81_triE & triE protein & 1.6 \\
\hline SOD_P4134 & SG0845 & Phage tail sheath protein & 1.8 \\
\hline SOD_P5250 & SG1123 & $\begin{array}{l}\text { Bifunctional } \\
\text { phosphoribosyl-AMP } \\
\text { cyclohydrolase/phosphoribosyl- } \\
\text { ATP pyrophosphatase }\end{array}$ & 1.6 \\
\hline SOD_P1745 & SG0267 & ADP-ribose pyrophosphatase & 1.4 \\
\hline SOD_P1747 & SG0267 & ADP-ribose pyrophosphatase & 1.3 \\
\hline SOD_P4134 & SG0845 & Phage tail sheath protein & 1.8 \\
\hline SOD_P8638 & SG1972_recD & Exonuclease $V$ subunit alpha & 1.7 \\
\hline SOD_P4186 & SG0858_nagB & $\begin{array}{l}\text { Glucosamine-6-phosphate } \\
\text { deaminase }\end{array}$ & 1.5 \\
\hline SOD_P7310 & SG1632 & Lipoprotein precursor & 1.3 \\
\hline SOD_P8638 & SG1972_recD & Exonuclease $V$ subunit alpha & 1.4 \\
\hline SOD_P4690 & SG0983 & Hypothetical protein & 1.7 \\
\hline SOD_P8662 & SG1978 & $\begin{array}{l}\text { Prolipoprotein diacylglyceryl } \\
\text { transferase }\end{array}$ & 1.6 \\
\hline SOD_P4186 & SG0858_nagB & $\begin{array}{l}\text { Glucosamine-6-phosphate } \\
\text { deaminase }\end{array}$ & 1.5 \\
\hline
\end{tabular}

The fold change represents the ratio of S. glossinidius gene expression level by comparing self-cured flies to control flies fed on a non-infected blood meal. 
calculation of relative expression quantification. Cycle thresholds $(\mathrm{Ct}$ ) for each reaction were obtained using the MxPRO QPCR Software (Agilent Technologies). Relative quantification was calculated with the $2^{-\Delta \Delta C(t)}$ method as described by Livak and Schmittgen (2001). Relative quantification for given genes with respect to the calibrator was determined and compared with the normalized expression values resulting from microarray experiments.

\section{RESULTS}

The aim of the study was, using the microarray analysis procedure, to compare the transcriptome of S. glossinidius harbored by tsetse flies (G. p. gambiensis) that got an non-infected blood meal (control flies) with that of the symbiont harbored by flies that did not become infected despite they were fed with T. $b$. gambiense infected blood meal (refractory flies). The comparison is expected to allow to identify differential expressed genes, if any. The gene expression was analyzed 10 days after the flies had taken either their infective or a noninfective blood meal. Two-class SAM procedures were used to identify differentially expressed genes with a $5 \%$ false discovery rate.

\section{IDENTIFICATION OF DIFFERENTIALLY EXPRESSED GENES}

Table 2 presents the 17 genes that exhibited significant differential expression between the two groups using the modified t-statistic SAM. Interestingly, all these genes were overexpressed in infection self-cured flies.

We used an unsupervised hierarchical clustering method that grouped genes on the vertical axis and samples on the horizontal axis, on the basis of similarity in their expression profiles. The similarities are summarized in a dendrogram in which the pattern and length of the branches reflect the degree of relatedness of the samples (Figure 1).

According to microarray data, all significantly differentially expressed genes were overexpressed 1.2 - to 1.8 -fold in

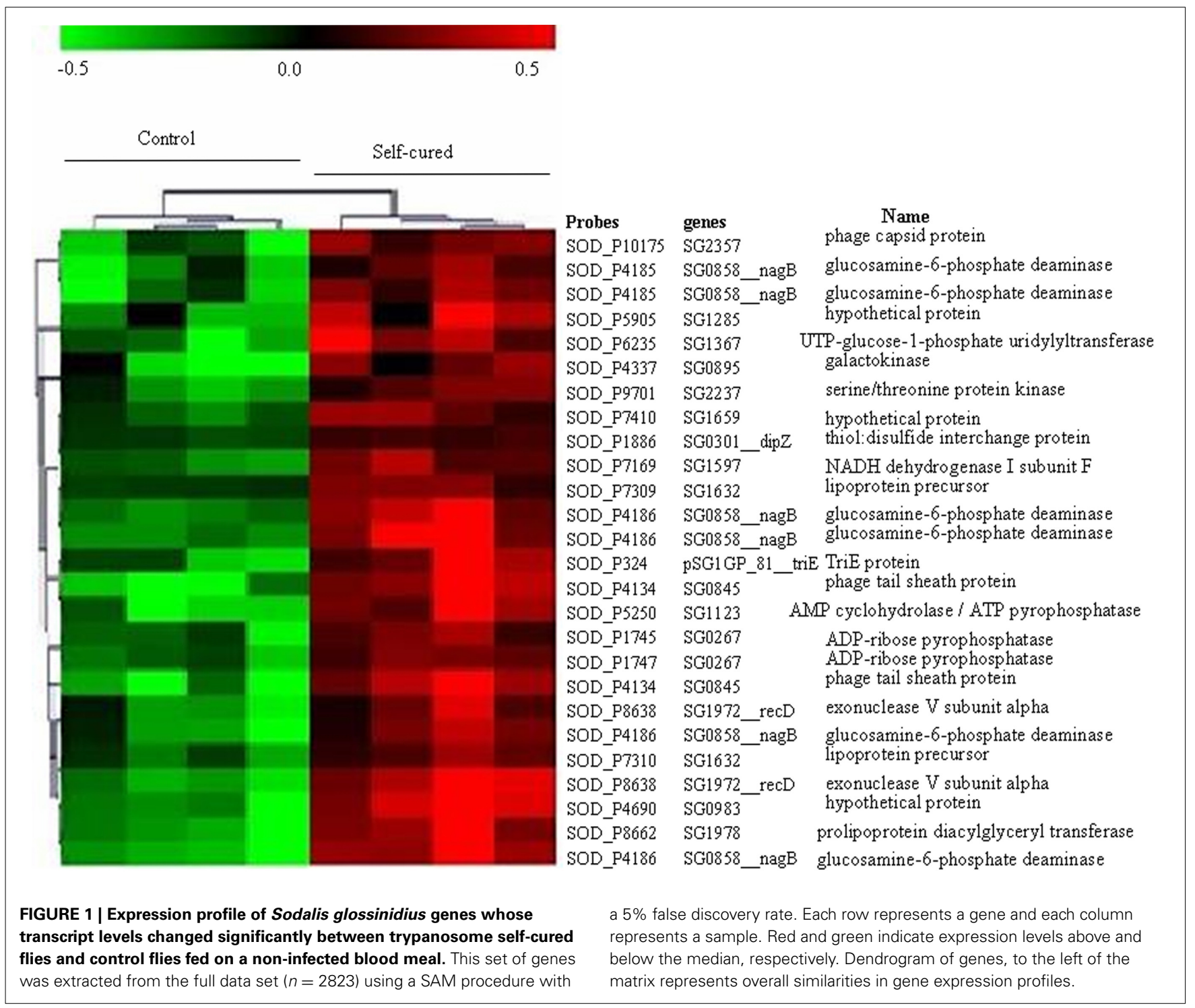


refractory flies with reference to the level of expression in control flies. The S. glossinidius gene (SG0858_nagB) corresponding to glucosamine-6-phosphate deaminase gene, is one of the most highly overexpressed in refractory flies (1.5- to 1.7-fold overexpression); this enzyme plays a crucial role in amino sugar and nucleotide sugar metabolism. We also detected increased expression levels of genes involved in purine metabolism such as ADP-ribose pyrophosphatase (SG0267; 1.4-fold increase), in $\mathrm{D}$-galactose metabolism, represented by the gene encoding galactokinase (SG0895) and UTP-glucose-1-phosphate uridylyltransferase (SG1367), which were 1.5- and 1.7-fold over-represented in refractory flies. Oxidative respiration complex enzyme $\mathrm{NADH}$ dehydrogenase (SG1597) appears to be 1.4-fold overexpressed in refractory flies.

In resistant flies, we also found overexpressed genes involved in the exonucleolytic cleavage of DNA, synthesis of amino acids and lipoproteins, as well as in disulfide bond formation and assistance in the conformational maturation of secreted proteins containing disulfide bonds.

Finally, among the highest overexpressed genes, we identified genes coding for phage tail sheath protein (SG0845; 1.8-fold overexpression) and for phage capsid protein (SG2357; 1.5-fold overexpression).

\section{qPCR CONTROL OF MICROARRAY DATA}

The microarray expression data were validated by quantitative PCR analyses. Four genes showing different expression levels were selected from the microarray data. The results provided by the quantitative PCR analyses were similar to those provided by microarray data, showing consistent expression levels for the four genes (Figure 2).

\section{GENE FUNCTIONAL ANNOTATION}

Functional annotations of the differentially expressed S. glossinidius genes, with reference to the biological process GO terms and KEGG pathways, was investigated using DAVID software. The analysis showed an overrepresentation of GO terms related to metabolism and biosynthesis processes (Table 3 ). The modified Fisher exact test revealed a 17.6-fold enrichment $(P$-value $=$ 0.055 ) for the GO term related to hexose metabolism (Table 3). Similarly, galactose metabolism KEGG pathways were found to be 28.5-fold-enriched $(P$-value $=0.088)$ (Table 4$)$.

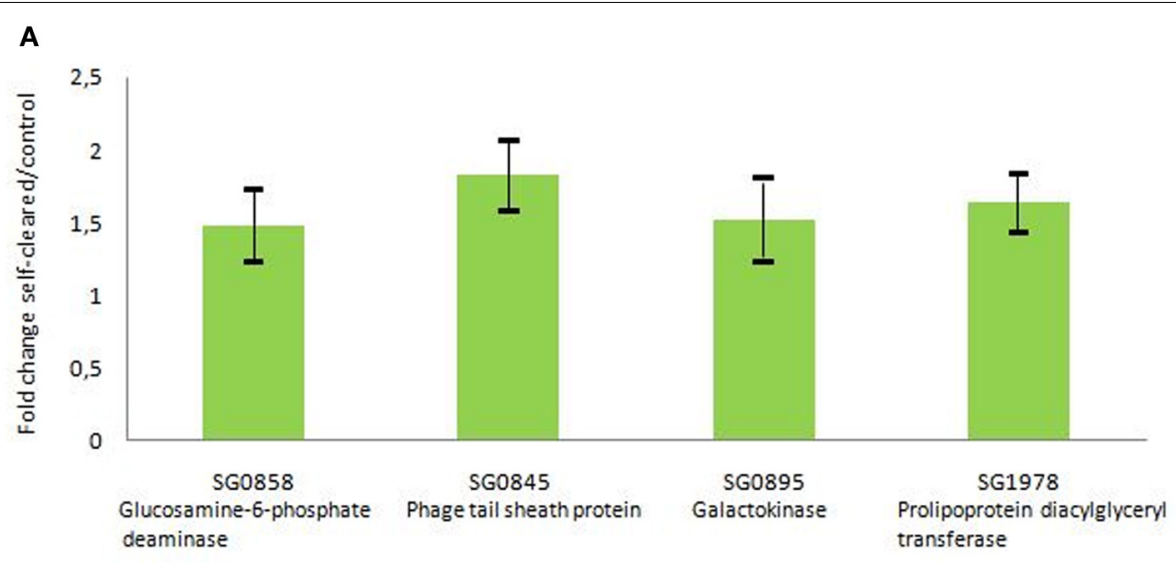

B

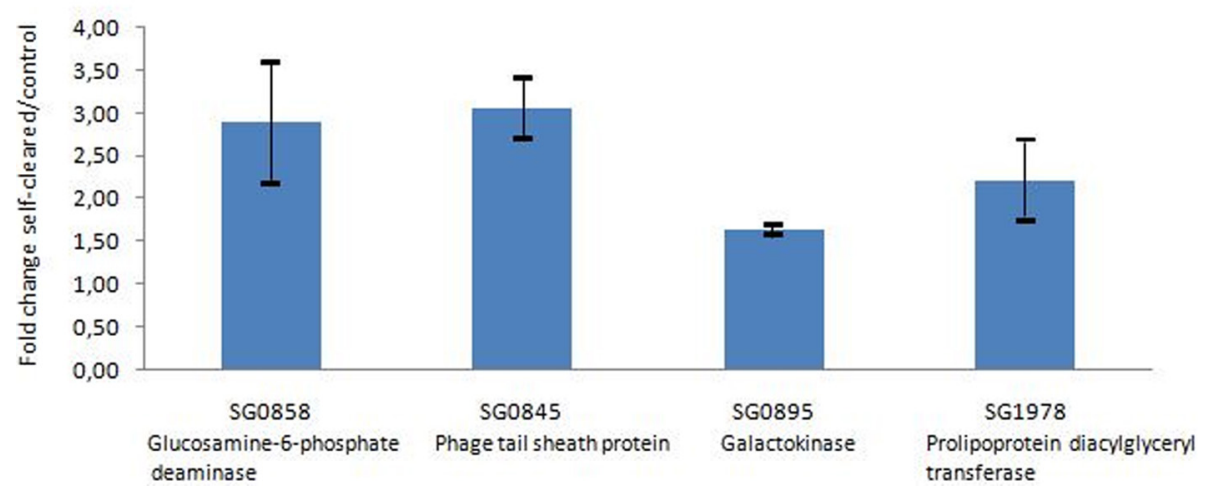

FIGURE 2 | Comparison of selected gene expression assessed by quantitative PCR and by microarray technologies. (A) Gene expression was assessed by microarray technology. The $\mathrm{n}$-fold change value was calculated on the basis of normalized data when comparing the level of gene expression from S. glossinidius derived from self-cured flies with those of control flies fed on a non-infected blood meal. Error bar represents the standard deviation (SD) between biological replicates. (B) Gene expression was assessed by quantitative PCR. Data were analyzed with the $2^{-\Delta \Delta C(t)}$ method with Glossina tubulin gene as a control gene. The $\mathrm{n}$-fold change value represents the mean of the Sodalis gene expression level in self-cured flies compared with control. Error bar represents the SD between biological replicates. 


\section{DISCUSSION}

After being ingested by a tsetse fly taking an infective blood meal, the trypanosome undergoes a complex cycle of differentiation and multiplication in the host midgut. Successful establishment of trypanosomes in the tsetse fly midgut depends on their ability to adapt, transform, grow, and survive rapidly in this new fly midgut environment (Simo et al., 2010). Several factors could influence parasite establishment, among which the tsetse midgut lectin (Welburn and Maudlin, 1999), reactive oxygen

\begin{tabular}{|c|c|c|}
\hline GO terms & & $\begin{array}{l}\text { Related gene } \\
\text { GenBank accession } \\
\text { number }\end{array}$ \\
\hline GO:0009249 & Protein lipoylation & SG1978 \\
\hline GO:0018065 & Protein-cofactor linkage & SG1978 \\
\hline GO:0042157 & Lipoprotein metabolic process & SG1978 \\
\hline GO:0042158 & $\begin{array}{l}\text { Lipoprotein biosynthetic } \\
\text { process }\end{array}$ & SG1978 \\
\hline GO:0005996 & $\begin{array}{l}\text { Monosaccharide metabolic } \\
\text { process }\end{array}$ & SG0895 \\
\hline GO:0006012 & Galactose metabolic process & SG0895 \\
\hline GO:0006793 & Phosphorus metabolic process & SG0895 \\
\hline GO:0006796 & Phosphate metabolic process & SG0895 \\
\hline GO:0016310 & Phosphorylation & SG0895 \\
\hline GO:0019318 & Hexose metabolic process & SG0895 \\
\hline GO:0046835 & Carbohydrate phosphorylation & SG0895 \\
\hline GO:0000105 & Histidine biosynthetic process & SG1123 \\
\hline GO:0006547 & Histidine metabolic process & SG1123 \\
\hline GO:0008652 & $\begin{array}{l}\text { Cellular amino acid biosynthetic } \\
\text { process }\end{array}$ & SG1123 \\
\hline GO:0009075 & $\begin{array}{l}\text { Histidine family amino acid } \\
\text { metabolic process }\end{array}$ & SG1123 \\
\hline GO:0009076 & $\begin{array}{l}\text { Histidine family amino acid } \\
\text { biosynthetic process }\end{array}$ & SG1123 \\
\hline GO:0009309 & Amine biosynthetic process & SG1123 \\
\hline GO:0016053 & $\begin{array}{l}\text { Organic acid biosynthetic } \\
\text { process }\end{array}$ & SG1123 \\
\hline GO:0018130 & $\begin{array}{l}\text { Heterocycle biosynthetic } \\
\text { process }\end{array}$ & SG1123 \\
\hline GO:0044271 & $\begin{array}{l}\text { Nitrogen compound } \\
\text { biosynthetic process }\end{array}$ & SG1123 \\
\hline GO:0046394 & $\begin{array}{l}\text { Carboxylic acid biosynthetic } \\
\text { process }\end{array}$ & SG1123 \\
\hline GO:0005996 & $\begin{array}{l}\text { Monosaccharide metabolic } \\
\text { process }\end{array}$ & SG1367 \\
\hline GO:0006006 & Glucose metabolic process & SG1367 \\
\hline GO:0006011 & UDP-glucose metabolic process & SG1367 \\
\hline GO:0009225 & $\begin{array}{l}\text { Nucleotide-sugar metabolic } \\
\text { process }\end{array}$ & SG1367 \\
\hline GO:0019318 & Hexose metabolic process* & SG1367 \\
\hline GO:0055114 & Oxidation reduction & SG1597 \\
\hline
\end{tabular}

${ }^{*}$ Enriched GO term with $t$-statistic modified test ( $P$-value $\left.=0.055\right)$ species (MacLeod et al., 2007), and antimicrobial peptide produced by the fly in response to trypanosome infection (Hao et al., 2001). Furthermore, S. glossinidius, was previously shown to favor tsetse fly infection by trypanosomes (Welburn and Maudlin, 1999). Despite the presence of the symbiont in all insectary tsetse flies, most of the flies are refractory to trypanosome infection (Geiger et al., 2005). In this context, we investigated the transcriptomic events that may occur in bacteria when they are harbored by refractory flies. Using microarray analysis we investigated S. glossinidius genes, the expression of which could discriminate G. p. gambiensis flies refractory to T. $b$. gambiense infection and control flies.

Most of the genes whose expression was modified, overexpressed in Sodalis from refractory versus Sodalis from control flies, are involved in lipoprotein metabolic and biosynthetic processes, as well as in amino sugar and nucleotide metabolism. Bacterial lipoproteins have been shown to play various roles, including nutrient uptake, transport (such as the ABC transport system), and extracytoplasmic folding of proteins (Lampen and Nielsen, 1984; Mathiopoulos et al., 1991; Alloing et al., 1994). The Sodalis prolipoprotein diacylglyceryl transferase gene (SG1978) that was found to be overexpressed in self-cured flies is the only one transferring the diacylglyceryl moiety to the thiol group of cysteine. The importance of this enzyme has been emphasized by the fact that post-translational modification is ubiquitous in the bacterial kingdom. The overexpression of enzymes involved in bacterial growth could be a necessary mechanism employed by the bacteria to fight the parasite.

The gene encoding the NADH dehydrogenase complex (SG1597) was found to be overexpressed in Sodalis from refractory flies. This enzyme is involved in the oxidative respiration process and allows bacteria to survive in a variety of hostile environments and to adapt quickly in a rapidly changing environment (Richardson, 2000). Furthermore, this enzyme is implicated in the synthesis of ATP, and thus energy metabolism in the prokaryotic cell (Lengeler et al., 2009). In mosquito cells, oxido-reduction mechanisms were used to protect against DENV viral infection (Patramool et al., 2011). Several other overexpressed genes in refractory flies were found to be involved in KEGG pathways and

\begin{tabular}{|c|c|c|}
\hline $\begin{array}{l}\text { KEGG } \\
\text { pathways }\end{array}$ & & $\begin{array}{l}\text { Related gene } \\
\text { GenBank accession } \\
\text { number }\end{array}$ \\
\hline sgl00230 & Purine metabolism & SG0267 \\
\hline \multirow[t]{2}{*}{ sgl00052 } & Galactose metabolism* & SG0895 \\
\hline & & SG1597 \\
\hline sgl00520 & $\begin{array}{l}\text { Amino sugar and nucleotide sugar } \\
\text { metabolism }\end{array}$ & SG0895 \\
\hline sgl00340 & Histidine metabolism & SG1123 \\
\hline sgl00040 & $\begin{array}{l}\text { Pentose and glucuronate } \\
\text { interconversions }\end{array}$ & SG1367 \\
\hline
\end{tabular}

${ }^{*}$ Enriched KEGG pathway with $t$-statistic modified test $(P$-value $=0.088)$ 
GO terms related to metabolism, such as galactose metabolism, purine metabolism, amino sugar and nucleotide metabolism, as well as hexose metabolism (Tables 3, 4). Thus, S. glossinidius might indeed benefit its tsetse host by nutrient supplementation via these compounds. However, why these pathways were overexpressed in refractory flies is unknown. In other studies, increased sugar metabolism enzyme activities due to viral infection have been reported (Klemperer, 1961; El-Bacha et al., 2004; Tchankouo-Nguetcheu et al., 2010). It has been suggested that the increased activity of glycolysis was due to the breakdown of the mitochondrial membrane, which decreased ATP production (Ritter et al., 2010). As a result, the glycolysis pathway was activated to compensate for the lack of energy via the oxidative pathway. However, recent studies have demonstrated alternative functions of sugar metabolism enzymes such as transcriptional regulation or as a regulator or indicator of apoptosis (Kim and Dang, 2005).

In addition, among the most highly overexpressed genes in refractory flies were those encoding glucosamine-6-phosphate deaminase (SG0858). This enzyme participates in amino sugar metabolism, particularly in the conversion of glucosamine into ammonium and fructose. S. glossinidius was suspected to favor trypanosome establishment in the insect midgut through a complex biochemical mechanism involving the production of $\mathrm{N}$ acetyl glucosamine (Welburn and Maudlin, 1999). This sugar, resulting from hydrolysis of pupae chitin by a S. glossinidiusproduced endochitinase was reported to inhibit a tsetse-midgut lectin lethal for the procyclic forms of the trypanosome (Dale and Welburn, 2001). So, while the presence of this sugar would favor the establishment of trypanosomes in the fly's midgut, its deamination by the glucosamine-6-phosphate deaminase may, in contrast, favor fly refractoriness. So in a next step, the decrease of $\mathrm{N}$-acetyl glucosamine in situ will have to be studied.

Finally, increased transcription of genes coding phage proteins was recorded in refractory flies when compared to flies fed with a non-infected bloodmeal. These results are in line with those obtained previously when comparing refractory versus infected flies (Hamidou Soumana et al., 2014). Bacteriophage elements have also been identified in other symbiotic associations. So for the presence of bacteriophages APSE- 1 and APSE- 2 in the secondary endosymbiont of aphids ca. Hamiltonella defensa where they are associated with the protective activity of this secondary endosymbiont that kills parasitoid wasp larvae (Oliver et al., 2003; Moran et al., 2005; Degnan and Moran, 2008). Similarly, a bacteriophage, WO, was characterized in parasitic Wolbachia; the phage was suggested to be beneficial for the invertebrate host as it may be involved in the parasitic bacterial load regulation (Bordenstein and Wernegreen, 2004; Bordenstein et al., 2006). Finally a detailed characterization of mobile genetic elements and pseudogenes revealed the presence of different types of prophage elements that have proliferated across the genome of S. glossinidius (Belda et al., 2010). In addition, the presence of viral particles has been observed previously in Sodalis glossinidius cultures (Maudlin, personal communication).

Regarding our results, they highlight the probable role of a bacteriophage as a major actor in tsetse fly refractoriness. The activation of a prophage hosted by $S$. glossinidius could lead to the release of bacterial agonists that trigger the tsetse fly immune system preventing trypanosome development.

The overall results demonstrate the existence of a molecular dialog between the three partners - the fly, the symbiont, Sodalis glossinidius, and the trypanosome-even though the parasite could not establish in the fly's midgut. Some of the overexpressed genes belong to classical metabolic pathways; others, however, may be involved in fly refractoriness. The molecular signal that induces the overexpression of all these genes is unknown. Further investigations are needed to progress in the understanding of the complex tripartite interactions that control the fly vector competence and hence the spread of sleeping sickness.

\section{ACKNOWLEDGMENTS}

The authors thank the "Région Languedoc-Roussillon - Appel d'Offre Chercheur d'Avenir 2011," the "Service de Coopération et d'Action Culturelle de l'Ambassade de France au Niger" and the "Institut de Recherche pour le Développement" for their financial support. Illiassou Hamidou Soumana is a $\mathrm{PhD}$ student funded by the French Embassy in the Republic of Niger, Service de Coopération et d'Action Culturelle (SCAC). We extend our thanks to Dr Aurélie Bergon (TAGC platform) for her assistance in data registration in the Gene Expression Omnibus data bank.

\section{REFERENCES}

Alloing, G., de Philip, P., and Claverys, J. P. (1994). Three highly homologous membrane-bound lipoproteins participate in oligopeptide transport by the Ami system of the gram-positive Streptococcus pneumoniae. J. Mol. Biol. 241, 44-58. doi: 10.1006/jmbi.1994.1472

Attardo, G. M., Lohs, C., Heddi, A., Alam, U. H., Yildirim, S., and Aksoy, S. (2008). Analysis of milk gland structure and function in Glossina morsitans: milk protein production, symbiont populations and fecundity. J. Insect Physiol. 54, 1236-1242. doi: 10.1016/j.jinsphys.2008.06.008

Balmand, S., Lohs, C., Aksoy, S., and Heddi, A. (2013). Tissue distribution and transmission routes for the tsetse fly endosymbionts. J. Invertebr. Pathol. 112, S116-S122. doi: 10.1016/j.jip.2012.04.002

Belda, E., Moya, A., Bentley, S., and Silva, F. J. (2010). Mobile genetic element proliferation and gene inactivation impact over the genome structure and metabolic capabilities of Sodalis glossinidius, the secondary endosymbiont of tsetse flies. BMC Genomics 11:449. doi: 10.1186/1471-2164-11-449

Bolstad, B. M., Irizarry, R. A., Astrand, M., and Speed, T. P. (2003). A comparison of normalization methods for high density oligonucleotide array data based on variance and bias. Bioinformatics 19, 185-193. doi: 10.1093/bioinformatics/19.2.185

Bordenstein, S. R., and Wernegreen, J. J. (2004). Bacteriophage flux in endosymbionts (Wolbachia): infection frequency, lateral transfer, and recombination rates. Mol. Biol. Evol. 21, 1981-1991. doi: 10.1093/molbev/msh211

Bordenstein, S. R., Marshall, M. L., Fry, A. J., Kim, U., and Wernegreen, J. J. (2006). The tripartite associations between bacteriophage, Wolbachia, and arthropods. PLoS Pathog 2:e43. doi: 10.1371/journal.ppat.0020043

Chen, X., Li, S., and Aksoy, S. (1999). Concordant evolution of a symbiont with its host insect species: molecular phylogeny of genus Glossina and its bacteriomeassociated endosymbiont, Wigglesworthia glossinidia. J. Mol. Evol. 48, 49-58. doi: 10.1007/PL00006444

Cheng, Q., and Aksoy, S. (1999). Tissue tropism, transmission and expression of foreign genes in vivo in midgut symbionts of tsetse flies. Insect Mol. Biol. 8, 125-132. doi: 10.1046/j.1365-2583.1999.810125.x

Cheng, Q., Ruel, T. D., Zhou, W., Moloo, S. K., Majiwa, P., O’Neill, S. L., et al. (2000). Tissue distribution and prevalence of Wolbachia infections in tsetse flies, Glossina spp. Med. Vet. Entomol. 14, 44-50. doi: 10.1046/j.13652915.2000.00202.x

Dale, C., and Welburn, S. C. (2001). The endosymbionts of tsetse flies: manipulating host-parasite interactions. Int. J. Parasitol. 31, 628-631. doi: 10.1016/S00207519(01)00151-5 
Dale, C., and Maudlin, I. (1999). Sodalis gen. nov. and Sodalis glossinidius sp. nov., a microaerophilic secondary endosymbiont of the tsetse fly Glossina morsitans morsitans. Int. J. Syst. Bacteriol. 49, 267-275. doi: 10.1099/0020771349-1-267

Degnan, P. H., and Moran, N. A. (2008). Diverse phage-encoded toxins in a protective insect endosymbiont. Appl. Environ. Microbiol. 74, 6782-6791. doi: 10.1128/AEM.01285-08

Dennis, G. Jr., Sherman, B. T., Hosack, D. A., Yang, J., Gao, W., Lane, H. C., and Lempicki, R. A. (2003). DAVID: database for annotation, visualization, and integrated discovery. Genome Biol. 4:P3. doi: 10.1186/gb-2003-4-5-p3

Doudoumis, V., Tsiamis, G., Wamwiri, F., Brelsfoard, C., Alam, U., Aksoy, E., et al. (2012). Detection and characterization of Wolbachia infections in laboratory and natural populations of different species of tsetse flies (genus Glossina). BMC Microbiol 1:S3. doi: 10.1186/1471-2180-12-S1-S3

El-Bacha, T., Menezes, M. M., Azevedo e Silva, M. C., Sola-Penna, M., and Da Poian, A. T. (2004). Mayaro virus infection alters glucose metabolism in cultured cells through activation of the enzyme 6-phosphofructo 1-kinase. Mol. Cell Biochem. 266, 191-198. doi: 10.1023/B:MCBI.0000049154.17866.00

Farikou, O., Njiokou, F., Mbida Mbida, J. A., Njitchouang, G. R., Djeunga, H. N., Asonganyi, T., et al. (2010). Tripartite interactions between tsetse flies, Sodalis glossinidius and trypanosomes-an epidemiological approach in two historical human African trypanosomiasis foci in Cameroon. Infect. Genet. Evol. 10, 115-121. doi: 10.1016/j.meegid.2009.10.008

Frézil, J. L., and Cuisance, D. (1994). Trypanosomiasis, diseases with future: prospects and uncertainty. Bull. Soc. Pathol. Exot. 87, 391-393.

Geiger, A., Ravel, S., Mateille, T., Janelle, J., Patrel, D., Cuny, G., et al. (2007). Vector competence of Glossina palpalis gambiensis for Trypanosoma brucei s.l. and genetic diversity of the symbiont Sodalis glossinidius. Mol. Biol. Evol. 24, 102-109. doi: 10.1093/molbev/msl135

Geiger, A., Ravel, S., Frutos, R., and Cuny, G. (2005). Sodalis glossinidius (Enterobacteriaceae) and vectorial competence of Glossina palpalis gambiensis and Glossina morsitans morsitans for Trypanosoma congolense savannah type. Curr. Microbiol. 51, 35-40. doi: 10.1007/s00284-005-4525-6

Hamidou Soumana, I., Berthier, D., Tchicaya, B., Thevenon, S., Njiokou, F., Cuny, G., et al. (2013). Population dynamics of Glossina palpalis gambiensis symbionts, Sodalis glossinidius, and Wigglesworthia glossinidia, throughout host-fly development. Infect. Genet. Evol. 13, 41-48. doi: 10.1016/j.meegid.2012. 10.003

Hamidou Soumana, I., Loriod, B., Ravel, S., Tchicaya, B., Simo, G., Rihet, P., et al. (2014). The transcriptional signatures of Sodalis glossinidius in the Glossina palpalis gambiensis flies negative for Trypanosoma brucei gambiense contrast with those of this symbiont in tsetse flies positive for the parasite: possible involvement of a Sodalis-hosted prophage in fly Trypanosoma refractoriness? Infect. Genet. Evol. 24C, 41-56. doi: 10.1016/j.meegid.2014.03.005

Hao, Z., Kasumba, I., Lehane, M. J., Gibson, W. C., Kwon, J., and Aksoy, S. (2001). Tsetse immune responses and trypanosome transmission: implications for the development of tsetse-based strategies to reduce trypanosomiasis. Proc. Natl Acad. Sci. U.S.A. 98, 12648-12653. doi: 10.1073/pnas.221363798

Herbert, W. J., and Lumsden, W. H. (1976). Trypanosoma brucei: a rapid "matching" method for estimating the host's parasitemia. Exp. Parasitol. 40, 427-431. doi: 10.1016/0014-4894(76)90110-7

Kim, J. W., and Dang, C. V. (2005). Multifaceted roles of glycolytic enzymes. Trends Biochem. Sci. 30, 142-150. doi: 10.1016/j.tibs.2005.01.005

Klemperer, H. (1961). Glucose breakdown in chick embryo cells infected with influenza virus. Virology 13, 68-77. doi: 10.1016/0042-6822(61)90033-2

Lampen, J. O., and Nielsen, J. B. (1984). N-terminal glyceride-cysteine modification of membrane penicillinases in gram-positive bacteria. Methods Enzymol. 106, 365-368. doi: 10.1016/0076-6879(84)06038-9

Lengeler, J., Drews, G., and Schlegel, H. (2009). Biology of the Prokaryotes. Stuttgart: Ed Blackwell Science.

Livak, K. J., and Schmittgen, T. D. (2001). Analysis of relative gene expression data using real-time quantitative PCR and the $2^{-\Delta \Delta C(t)}$ method. Methods 25, 402-408. doi: 10.1006/meth.2001.1262

MacLeod, E. T., Maudlin, I., Darby, A. C., and Welburn, S. C. (2007). Antioxidants promote establishment of trypanosome infections in tsetse. Parasitology 134, 827-831. doi: 10.1017/S0031182007002247

Mathiopoulos, C., Mueller, J. P., Slack, F. J., Murphy, C. G., Patankar, S., Bukusoglu, G., et al. (1991). A Bacillus subtilis dipeptide transport system expressed early during sporulation. Mol. Microbiol. 5, 1903-1913. doi: 10.1111/j.13652958.1991.tb00814.x
Maudlin, I., and Ellis, D. S. (1985). Association between intracellular rickettsialike infections of midgut cells and susceptibility to trypanosome infection in Glossina spp. Z Parasitenkd 71, 683-687. doi: 10.1007/BF00925601

Maudlin, I., and Welburn, S. C. (1994). Maturation of trypanosome infections in tsetse. Exp. Parasitol. 79, 202-205. doi: 10.1006/expr.1994.1081

Moran, N. A., Degnan, P. H., Santos, S. R., Dunbar, H. E., and Ochman, H. (2005). The players in a mutualistic symbiosis: insects, bacteria, viruses, and virulence genes. Proc. Natl. Acad. Sci. U.S.A. 102, 16919-16926. doi: 10.1073/pnas.0507029102

Moser, D. R., Cook, G. A., Ochs, D. E., Bailey, C. P., McKane, M. R., and Donelson, J. E. (1989). Detection of Trypanosoma congolense and Trypanosoma brucei subspecies by DNA amplification using the polymerase chain reaction. Parasitology 99, 57-66. doi: 10.1017/S0031182000061023

Oliver, K. M., Russell, J. A., Moran, N. A., and Hunter, M. S. (2003). Facultative bacterial symbionts in aphids confer resistance to parasitic wasps. Proc. Natl. Acad. Sci. U.S.A. 100, 1803-1807. doi: 10.1073/pnas.0335320100

Patramool, S., Surasombatpattana, P., Luplertlop, N., Sévéno, M., Choumet, V., Thomas, F., et al. (2011). Proteomic analysis of an Aedes albopictus cell line infected with Dengue serotypes 1 and 3 viruses. Parasit Vectors 4:138. doi: 10.1186/1756-3305-4-138

Penchenier, L., and Itard, J. (1981). Une nouvelle technique de dissection rapide des glandes salivaires et de l'intestin de glossines. Cah. ORSTOM Serie Ent. Méd. Parasitol. 1, 55-57.

Ravel, S., Grébaut, P., Cuisance, D., and Cuny, G. (2003). Monitoring the developmental status of Trypanosoma brucei gambiense in the tsetse fly by means of PCR analysis of anal and saliva drops. Acta Trop. 88, 161-165. doi: 10.1016/S0001706X(03)00191-8

Ravel, S., Patrel, D., Koffi, M., Jamonneau, V., and Cuny, G. (2006). Cyclical transmission of Trypanosoma brucei gambiense in Glossina palpalis gambiensis displays great differences among field stocks isolates. Acta Trop. 100, 151-156. doi: 10.1016/j.actatropica.2006.09.011

Reiner, A., Yekutieli, D., and Benjamini, Y. (2003). Identifying differentially expressed genes using false discovery rate controlling procedures. Bioinformatics 19, 368-375. doi: 10.1093/bioinformatics/btf877

Richardson, D. J. (2000). Bacterial respiration: a flexible process for a changing environment. Microbiology. 146, 551-571.

Ritter, J. B., Wahl, A. S., Freund, S., Genzel, Y., and Reichl, U. (2010). Metabolic effects of influenza virus infection in cultured animal cells: Intra- and extracellular metabolite profiling. BMC Syst Biol. 4:61. doi: 10.1186/1752-0509-4-61

Simo, G., Herder, S., Cuny, G., and Hoheisel, J. (2010). Identification of subspecies specific genes differentially expressed in procyclic forms of Trypanosoma brucei subspecies. Infect. Genet. Evol. 10, 229-237. doi: 10.1016/j.meegid.2009.11.003

Tchankouo-Nguetcheu, S., Khun, H., Pincet, L., Roux, P., Bahut, M., Huerre, M., et al. (2010). Differential protein modulation in midguts of Aedes aegypti infected with chikungunya and dengue 2 viruses. PLoS ONE 5:e13149. doi: 10.1371/journal.pone.0013149

Welburn, S. C., Arnold, K., Maudlin, I., and Gooday, G. W. (1993). Rickettsia-like organisms and chitinase production in relation to transmission of trypanosomes by tsetse flies. Parasitology 107, 141-145. doi: 10.1017/S003118200006724X

Welburn, S. C., and Maudlin, I. (1999). Tsetse-typanosome interactions: rites of passage. Parasitol. Today 15, 399-403. doi: 10.1016/S0169-4758(99)01512-4

Conflict of Interest Statement: The authors declare that the research was conducted in the absence of any commercial or financial relationships that could be construed as a potential conflict of interest.

Received: 29 March 2014; paper pending published: 22 April 2014; accepted: 09 May 2014; published online: 27 May 2014.

Citation: Hamidou Soumana I, Tchicaya B, Loriod B, Rihet P and Geiger A (2014) Identification of overexpressed genes in Sodalis glossinidius inhabiting trypanosomeinfected self-cured tsetse flies. Front. Microbiol. 5:255. doi: 10.3389/fmicb.2014.00255 This article was submitted to Microbial Symbioses, a section of the journal Frontiers in Microbiology.

Copyright (c) 2014 Hamidou Soumana, Tchicaya, Loriod, Rihet and Geiger. This is an open-access article distributed under the terms of the Creative Commons Attribution License (CC BY). The use, distribution or reproduction in other forums is permitted, provided the original author(s) or licensor are credited and that the original publication in this journal is cited, in accordance with accepted academic practice. No use, distribution or reproduction is permitted which does not comply with these terms. 